\title{
An empirical study of consumer behavior in housing market in Colombo
}

\author{
R G Ariyawansa
}

\begin{abstract}
This study aims to provide a scientific insight into the consumer behavior of the housing market in Sri Lanka. Consumer behavior in the housing market presents a veritable problem to be reckoned with, which might not yet been addressed scientifically. The broader objective of the study is, therefore, to add the knowledge of consumer behavior of housing market in Sri Lanka to the existing body of knowledge. Further, it is expected, especially, to identify the determinants of the consumer behavior, to rate them in terms of importance, and to compare the relative importance of the determinants among different market segments.

This study disclosed a number of attributes of the market according to the potential buyers' views in relation to buying decision of a house. $35 \%$ of the respondents stated that they would like to buy built houses rather than engage in construction. Further, it was identified that "location" of a house is the most important determinant of the buying decision. However, it is not the dominant factor because some other factors such as "quality of construction", "price", "legality", "facilities", "neighborhood" are also more important closely as important as the location. The other revealed fact is that the demographic variables such as age, income levels, and occupation are not highly effective criteria for the segmentation of the housing market.
\end{abstract}

Accordingly, it is certain that this study provides a valuable supplementary to the existing literature of the marketing management through imparting the knowledge of the consumer behavior of the housing market in Sri Lanka.

\section{Introduction}

The knowledge of the buyer behavior of the target market is essential in marketing a product. Basically buyers are of two types. One is buyer for consumption and the other one is the business buyer. Consumer and business buying behavior vary largely due to some factors prevailing internally or externally to the person and to the product. Factors associate with the person are age, sex, education, social levels, culture etc. Price, quality, appearance, legibility, etc; are also associated with a product. Buyer behavior is influenced by four main factors such as cultural, social, personal, and psychological (Kotler et. al. 2007; Kotler, 1991).

Since housing, as a real estate product, plays a vital role in any economy, studies on housing is virtually important. In Sri Lanka, real estate is a booming industry in which research and development have been improved to a certain extent. Meanwhile the subject of marketing management is also being recognized as an important area for every economic activity. However, it is able to see only a few scientific studies on marketing aspects in real estate businesses in Sri Lankan context. Hence, this study attempts to fill the knowledge gap in the housing market relating to the buying behavior.

On the other hand, some of the real estate development in Colombo as Achelon square, JAIC-Hilton Tower, and condominiums such as Royal Park, Crescat, Kings Court, Ceylinco-Seylan Tower etc; stimulates the studies on real estate markets. Moreover, some innovative forms of private housing projects such as the Millennium City increase the need of market studies in the housing sector of the country.

As far as the available market opportunities in Colombo metropolitan are concerned, housing market related research would widely be useful. For instance, in 1994, the housing deficit in the Colombo Municipal Council (CMC) area was $41.3 \%$ of the total housing deficit of the country (Jagoda, 2000). Further the permanent housing in the area of CMC is only $62.6 \%$. Estimates have predicted that Colombo metropolitan region needs 375,800 housing units by the year 2010 to cater the additional demand (CMRMP, 1998 in Jagoda, 2000). These statistics generally imply the scope of the potential housing demand at present and in the near future in the study area.

In this context, this study aims to fill the knowledge gap of those who are engaged in housing market activities such as developers, investors, buyers, sellers and scholars etc. To achieve the aim following specific objectives are incorporated.

I. To gather and examine existing theories \& work related to buyer behavior related to the housing market

II. To identify determinants of buyer behavior in the area of private housing 
III. To rate the relative importance of the determinants of the buying decision of private housing

IV. To examine the relative importance of identified determinants according to market segments based on income, age, occupation, and sex

\section{Methodology}

\section{Research questions:}

Following specific questions are addressed in the study.

I. Which factor is relatively more important in a buying decision of a house?

II. How does the relative importance vary according to different market segments in the housing market?

III. Is the segmentation of housing market effective and meaningful according to the demographic factors as age, sex, income, and occupation?

This empirical research used both primary and secondary data. Secondary data was gathered from institutes engaged in housing market activities as well as reports, books, research works. For primary data, a sample of 100 potential housing buyers was used.

To collect primary data a structured questionnaire and interview methods were mainly used. The questionnaire was prepared by means of pre-discussions with potential buyers, real estate brokers and sellers. Following model was used to provide the basic principle for the study.

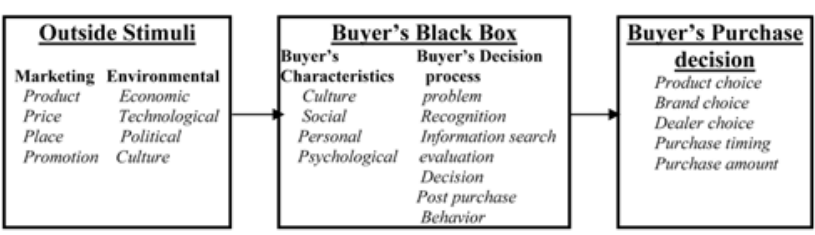

Figure No. 01 - Buyer Behavior Model:

Source: Kotler, (1991) p 164

However, in this study, "consumer's outside stimuli" and buyer's characteristics are mainly evaluated. These factors are related to the housing product as follows.

- Product: Quality, Design, Size, In-built services, Warranties, ....etc;

- Price: List price, Discount, Allowances, Payment period, ....etc;

- Place: Location, infrastructure facilities, Immediate vicinity, ...etc;

- Promotion: Sales promotion, Advertising, ....etc;

- Economic: Purchasing power, Spending pattern, ...etc;

- Technological: New facilities, Innovations, ...etc:
- Political: Legal background, Government intervention, ...etc:

- Culture: Race, Religious, ...etc;

- Social: Family status, ....etc;

- Personal: Age, Occupation, Lifestyle, ...etc;

- Psychological: Motivation, Perception, Beliefs and Attitudes, ...etc;

\section{Analysis}

(a) General statistics as Mean, Mode, Medium, Percentage, Probability concepts are applied for the descriptive analysis

(b) A Weighted Score technique is used to answer the research questions.

Total Weighted Score (TWS), percentages of Total Weighted Scores (\% TWS), and Weighted Averages (WA) which describe the phenomenon pertaining to a particular determinant were computed. The factor, which received the highest value of "TWS", "\% of TWA", and "WA" can be identified as the most relatively important factor.

(c) Chi - Square test

The Chi - Square test can be used to investigate the relationship between two categories of variables as to whether they are independent or dependent. This statistically tests two hypotheses. They are,

- Ho: Two categories of data are independent.

- H1: Two categories of data are dependent.

In this way, a statistic is computed by,

$$
\begin{gathered}
x^{2}=\Sigma\left[\left(O_{i j}-E_{i j}\right)^{2} / E_{i j}\right] \\
E_{i j}=\left[\left(R_{1}\right)\left(C_{j}\right)\right] / T
\end{gathered}
$$

$v=(K-1)(h-1)$ is the degree of freedom

For this analysis, each demographic variable (age, sex, occupation, income) was taken as one category. And the set of the other determinants (location, price, quality... etc) was taken as the other category. Thus, a table consists of "WTS" or "WA" of determinants is the contingency table for the chi-square test for independence.

(d) Rank Correlation coefficient

This was used to evaluate further the viability of demographic factors as market segmentation. The rank correlation coefficient estimates the degree of the relationship between two ranked data series. If "X" \& "Y" are two variables, which have series of ranked data, then the correlation between them is expressed mathematically as,

$r_{k}=\left\{1-\left[\left(6 \Sigma d_{i}^{2}\right) /\left(n\left(n^{2}-1\right)\right]\right\}\right.$

If $r_{k}>0$ Ranked series of data have the same pattern. 


\section{Limitations of the research}

- The study is confined to the consumer's point of views, attitudes, values etc; rather than those of sellers.

- For this study gross salary of employees is only considered to group them into income categories.

- The study focused on housing product offered by the private sector.

- The study focused the Colombo metropolitan as the study area

- Market segmentation are taken as,

o Age: 25-35 years, 36-45 years

$0 \quad$ Sex: Male and Female

o Monthly income: Bellow Rs.5000/=, Rs. $5001 /=-$ Rs. $10000 /=$, Rs. $10001 /=-$

Rs. $15000 /=$, Rs. $15001 /=-25000 /=$, Above

Rs. $25001 /=$

- Occupation: Bellow clerical, Clerical, Middle level managers/executives, Managers/ executives

\section{Determinants of consumer buying decision of a house}

\section{Consumer behavior in general}

In order to achieve the success of a firm, it needs to provide to target markets with more value than what competitors provide (Hawking et. al.1995, p.7). Therefore, to achieve the goal, it must have a crystal clear knowledge of consumer's needs, wants, desires, and expectations etc. To identify such aspects, it is needed to comprehend the consumer behavior thoroughly.

How does a marketer provide a superior value for its target market? Marketing manager and all find the solution for this question normally through marketing strategy. The marketing strategy is basically formulated in terms of so-called marketing mix i.e. product, place, price, and promotion (4Ps) (Kotler, 1991). In fact, this is a combination of elements that meets the consumer's needs in providing certain values. Therefore, it can be pointed out that the consumer should be the focal point of marketing strategies.

The consumer behavior refers to as simply the purchasing decision of a particular product or a service. Purchasing decision is, in fact, a highly complex one, subject to wide variety of inter-related economic and behavioral influences (Morden, 1991, p.147). Consumers' internal elements as desires, expectations, attitudes etc are highly subjective. On the basis of this internal situation, he/she learns and obtains experience from the external environment. Then having reformed the initial base, he/she tries to perceive on elements of the environment again. Ultimately the consumer behavior is determined by his internal characteristics in collaboration with the external characteristics of the macro environment. Accordingly, a firm is required to collect ample information to study the consumer behavior.

A house, as a real estate product manifests very distinct characteristics and it influences heavily on each and every aspect of human beings. Hence, it can be argued that there is a type of complex buying behavior in the housing market. According to marketing analysis, consumer durables can be put into the category of complex buying behavior that associates high involvements and significant brand difference among products (Kotler, 1991). In many writings, color television sets, automobiles etc; have been taken as examples of consumer durables. A house can also be identified as a consumer durable though it contains some distinct features.

\section{Determinants of consumer behavior}

Consumer behavior models such as "Types of Buying Behavior" (Kotler, 1991 p. 179); "Buyer Behavior Model" (Kotler, 1991 p 164); "Consumer buying decision process", (William et al, 1994 p.15); and "Overall model of the consumer behavior" (Hawkins, et al, 1995 p .02) reveal that the consumer behavior is complicated and thereby recognizing of determinants is difficult. However, these models help to identify consumer's outside and inside stimuli in buying decision in general. To the outside of the buyer, marketing mix i.e. product, price, place, promotion and environment factors as economic, technological, political, cultural etc; influence to the consumer behavior widely. Meanwhile factors internal to the consumer as cultural, personal, social, psychological etc; shape and form the buying behavior as well (William, 1978 p.133).

All these could be classified broadly as product-related characteristics, personal characteristics and the situational characteristics in the event of formulating marketing strategy (Hawkin, et. al., 1995, p.21).

Personal characteristics: Each customer is a kind of unique person. Marketers attempt to group those who are similar, rarely identical, into market segments. For instance, using demographic variables such as age, sex, income and occupation etc consumer can be categorized into specific market segments.

Product-related characteristics: From product to product it is different in several aspects. For example, in contrast to non-durables, purchase of durable goods are often proceeded by a progression of interacted decisions and activities through time, husband, wife, and even children are getting more opportunities to involve in buying decision at one or more instances (Harry, 1976, p.244).

Situational characteristics: All the other factors excluding the above two are situational characteristics. Legal, economic, etc and of all the macro-environment are concerned under this category. 


\section{Consumer behavior in the housing market}

The marketing of a real estate product like house is a more complicated process than that is involved in most other section of the economy (Weimer, 1960 p. 184). In fact, the real estate market can be defined as a place where real estate marketing decisions i.e. decision of buying or selling at which price, at what terms, at what time etc by interaction of property owners and prospective owners are taken place. In fact, such marketing decisions are based on income producing in money term or direct use of the property.

Characteristics of a house as a real estate product A house includes a plot of land, building and other improvements as well as the legal rights represented by these physical components. All real estates can be identified as residential, commercial, industrial, public, and special purpose properties. Housing is one of these mentioned, as the residential purpose real estate. Regardless of the type of the real estate, they possess very particular economic and physical characteristics; thereby the consumer behavior in this market becomes a specific phenomenon.

Immovability: The fixed location of a house is an underlined feature of a product of this kind. Since the land is naturally fixed, immovability of a house is inevitable. Therefore, the cost of moving a house is too big and it happens very rarely. Due to the fixity of the location, each house is different from another. Further, because of the fixity of location, the housing market tends to be too limited in extent than the markets for many other goods and services. For example, for owner occupied houses, market is limited to a certain area. In case of a commercial or office space, the market is wider.

Lifetime: Comparatively a long life of a house is the other salient feature, which influences the buying decision in any situation. As far as a land is concerned, it is indestructible. Even a house, which is properly built, exists perhaps more than two or three generations. It also can be renovated and in turn extended its lifetime. Thus, the lifetime is also a significant attribute of a house, which consciously affects to the consumer buying decision. In case of a commodity like cloth or food, consumer does not hesitate to make even an inappropriate decision in purchasing. However, on real property, relatively a very big attention is conveyed in buying decision.

Cost: Other influential factor, in determining a housing transaction is that the amount of money spent on a house. It is an enormous amount compared to the other expenses during the whole lifetime of a person. Since a house is a large economic unit of a family or an organization, special financial arrangements are most probably required.

Complementary products and services: A house cannot be used alone. A number of other basic products so-called infrastructure facilities such as water, electricity, accessibility, sanitation, etc; are indispensable to make a house usable in the least condition. Apart from these, today various types of other facilities are essential to make a house more convenient and habitable. Therefore the quality of construction, size of the house, legal condition, design, and the environmental situation etc; are also prior to all terms in determining the transaction of a house. And, also factors like material of construction, style of architecture, distance of transportation from working places, civic and social centers etc; differentiate a house from another house.

Value appreciation in the future: The behavior of the current macroeconomic variables indicates a significant nature in determining the money value and the value of immovable property like a house. Value of money in Sri Lanka is normally being depreciated. Therefore, keeping wealth in money terms in hand or other ways are more costly. Meanwhile, the real estates are often in the habit of value appreciation. Therefore, house becomes a specific economic unit for a person in terms of amassing the wealth.

Thus, from a buyer's point of view the demand for a house as a real estate product (a land and a building) is based on a wide range of considerations such as the standards, attitude and objectives of individuals, family, business firms, government officials and others (Weimer, 1960 p.185). In the case of commercial and industrial properties, however, demand is a reflection of profit earning capacity of related firms. Firms demand more real property when the market for their product is higher. Similarly, the demand for residential real estate is largely a reflection of consumer's income. The principal demand factors are the trends of employment and incomes of the potential customer group and the terms and availability of finance etc (Weimer, 1960, p.107).

It is said that a house presents as a symbol of status/ achievement or social acceptance and stimulates capital investment of the people (Sumanasekare, 1996). Therefore, one who wants to buy a house goes through a very intensive search of information so that he/she can verify and buy the correct thing. The consumer's buying behavior manifests both rational and emotional behaviors (Vipula, 1995). Since a house is a culture specific superlative consumer durable and it influences each and every aspect of a person, who is very keen on factors such as the price, physical condition (quality), design and location, infrastructure facilities, and legal conditions etc; in purchasing a house. Zainuddin, et al (2006) has pointed out six major factors for customer attraction for housing estates as location, design, price, supplier's reputation, quality of product, and services.

The other important factor is that buyers find different benefits from a house in a particular time in a suitable space. Hence, a marketer or a manager should first think of the function, time, and required space expected 
by the customer in formulating housing market decisions (Apgar, 1995). Here, the function implies the benefits expected by the consumer. Time means when it is used. Space is simply the size.

The location of the house is a very important factor for the information of the residential property purchaser. According to Nanayakkara et al (2006) the most significant factor for a customer to select an apartment is the location. Other important factors are facilities, design of the property, regular maintenance and regular supply of services such as water, electricity and proper solid waste management system in connection with apartment housing. Infrastructure facilities, accessibility, healthy environment etc. are centered and interconnected with the location and such variables are highly concerned in purchasing a house. In Sri Lanka, however, private sector houses provide such facilities inadequately (Ratnayake, 1991). In the case of accessibility the demand behavior of consumers who commute regularly to the Central Business District (CBD) selecting housing and non-housing consumption and residential location subject to a monetary budget constrains capturing the infra-urban area travel (Turabull, 1992). In addition, healthy and habitable environment also depends on the location of the residence. The rich and the middle class people abandon the city limits leaving the poor in the over crowed city areas searching more comfortable survival, as city becomes congested (Saunders, 1990).

Thus, the immediate neighborhood is also highly concerned by potential housing buyers. Health, calm and quietness, secure, and privacy etc; are some common expectations for every person in finding a habitable living place. According to the demand pattern of condominium in Colombo, semi luxury apartments are popular among migrant workers, who can buy such unit with their foreign earnings and live peacefully after their return or retirements (Wejeweera, 2003). A research has found that a situation of a particular kind of neighborhood occupied by particular sort of severely mentally disable clients can make a large, statistically significant reduction of nearby property value, at least in the short run (Golster et al, 1994). This implies that there is a less demand for such properties surrounded by poor immediate neighborhood environment. "An analysis of house sale surrounding Michigan hog operation areas" has disclosed that the value of a house has been decreased by US $\$ 43$ for each additional hog within a five miles radius (Pulmquist, 1997). Similarly, the urban residential land values vary considerably due to the environmental quality such as scenic beauty (Prematilake, 1999).

The financial attribute of the buyer i.e. the ability to pay easily is another determinant of the buying behavior. There is a positive relationship between source of credibility and the propensity to buy, which exists only for the high-involvement product and the upper-middle class category (Vipula, 1995).
The time spent on searching information affects to the consumer behavior in buying decision too (Tunbull, 1992). For many consumer durable goods, consumers are used to reduce the risk of making a wrong choice by searching a perfect set of information regarding the product, visiting the product etc (Glen L. Urban et al, 1993). A very particular example regarding the importance of the correct information is that an imperfect information of the 1989 Loma Prieta earthquake hazard caused to an unexpected price reduction of properties (Beron, et al, 1997).

With the view of the fact, it is clear that the knowledge of the housing market is important for both the buyers as well as to the producer. In Sri Lanka, some marketing implications are prevailing due to the lack of market information and imperfect knowledge among sellers and buyers (Prematilake, 1999). Thus, it can be argued that at least the producer, who is supposed to be a caretaker of the consumer, should have a well understanding of the need and the behavior of the consumer.

Moreover, in a broader sense, the population-structures and the socio-economic situation, etc; widely determine the housing market transaction of any economy. Higher number of middle aged group of population leads to a higher demand for family items such as clothes, food, and housing and increase of the segment of people starting the new families will expand the market for housing (Nickels, 1982). A study based on Nigerian data reveals "the most important determinants of demand for the various housing attributes are the socio-economic and the demographic nature of human beings, income, price, household size, occupation of the head of the household, and the stage of the family life cycle" (Arimah, 1992).

\section{Widely considered housing attributes}

According to the available literature, with the help of author's experience and looking over the market important housing attributes are picked up for the empirical test.

Quality of construction: In technical terms, a house is a structure, which comprises of three main components as the floor, walls and the roof. The durability, strength, appearance, cost of construction, maintenance, and all of a housing unit largely depend on the quality of construction of these main three components. Therefore, the quality of material used, the technology applied etc; are very important in this regard.

Location: Simply, with regard to a house, the location refers to a place on a given area of surface on the earth. This is important in two aspects. One is the importance of the location in connection with the immediate surrounding, which determines a number of necessities for the living such as facilities, accessibility, privacy, calm and quietness, and the other socioeconomic variables. The other one is, in broader sense, the location 
differentiates the regional attribute of a house. Whether it is located in a city, village, or in a suburban etc; is very important in today's housing market.

Price: Price still remains as a critical decisive factor in purchasing of many products. For a house as an extreme consumer durable, the degree of importance of this factor is often higher. In spite of the enhanced role of the other non-price factors, the price holds a challenging and critical element in monopolistic competitive markets (Kotler, 1972, p.503). Since the housing market is also operating as an imperfect state, likely monopolistic competitive market, the pricing factor plays a vital role in marketing decisions.

Design: Just like an augmented product of the housing, the design of a house makes greater influence to the buyer's choice. This addresses to the psychological needs of the consumer. This helps to differentiate the product easily too.

Size: This is of course a kind of expected product of a house rather than the core benefit. Size of the total house or each essential section should suit to the buyers' needs and desires.

Facilities: This is also a kind of expected product rather than the core benefits. Nowadays these are highly considered and demanded. Various kinds of facilities are demanded to fulfill survival needs, security needs social needs, esteem needs or self-actualization needs by a person.

Legal environment: This is important in many aspects. Legal transactions are expected by all the civilized societies. Remarkably for real estate product (land and buildings), all the good qualities and aspects depend on the legal feasibility of the product. This is also able to put into the category of product-related factors.

Neighborhood surround: All individuals as well as their unique social groups have their own pattern of living. The neighborhood environment greatly affects in numerous ways on personal needs as well as needs of the family, which in fact a very distinct group of the society

Additional sections as a garage, parapet wall, swimming pool etc: This is also another type of augmented product relating to a house. A servant room and a toilet, a garage, balcony, and a gate with the surrounding parapet wall etc; are in addition to the core benefit of a house.

All the above ten factors can be arranged under the elements of the marketing mix. However, this arrangement may be a controversial and may not be highly valid for every type of housing market studies.
For this study about the potential buyers' views and expectations, the following model is applied.

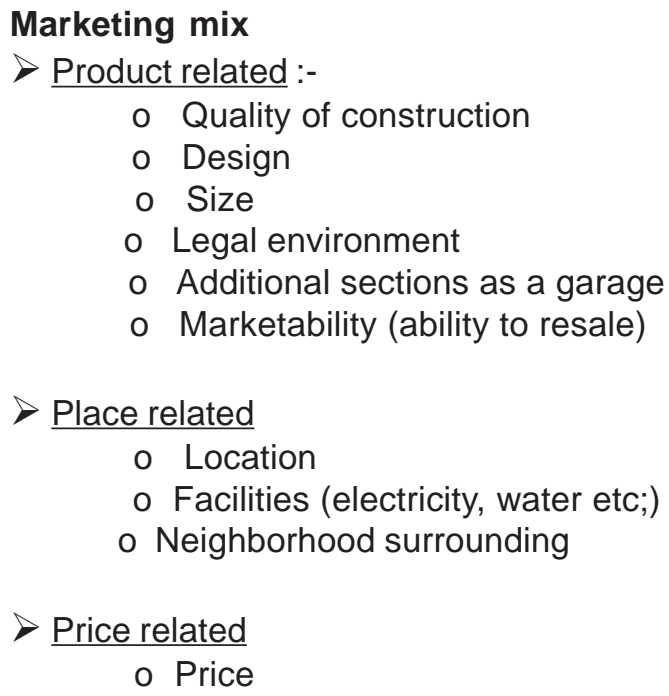

Promotion related :- No promotional mix element in the above list.

This is, of course, on the basis of an argument that is according to the explanation made by Kotler (1972, p. 72) with the help of the figure titled "3.7 - factors influence to the company marketing strategy". It clearly states that the target customers are in the middle of all the factors. Marketing mix is in between the customer and all the other factors. It implies that all the factors affect on the consumer behavior through the marketing mix finally. Therefore, there is a valid point in the above argument.

\section{Findings of the study}

\section{Some general preferences to housing attributes} The ownership of a house: $97 \%$ respondents prefer to have freehold interest of a house. Only $3 \%$ prefer to a rented house. Regarding this, Saunders' (1990) examination on homeownership also reveals that there is clear evidence as to homeowners are generally much happier than the council tenants even in England.

About the arrangement of a house: $99 \%$ wish to have separated houses while $1 \%$ consents to buy a house in a scheme. And no one is willing to be in an annex as his or her permanent residence at all.

About the structure of a house: $58 \%$ prefer to single storied houses and $41 \%$ like to find their residence in a two-storied house. Only $1 \%$ stated their willingness for three or more storied house.

About the location of a house: $60 \%$ like to reside in suburban areas while $23 \%$ prefer to be in a city center. And $17 \%$ prefer to choose their residence in villages. 
A summary of potential consumers' willingness for the ownership, structure, arrangement, and the location of a house as discussed above is as follows.

\begin{tabular}{lll} 
Attributes & \multicolumn{2}{l}{ \% Preferences for each attribute } \\
Ownership & FH (97\%) & RE $(3 \%)$ QA $(0 \%)$ \\
Structure & SS $(58 \%)$ & TS $(41 \%)$ TM $(1 \%)$ \\
Arrangement & SE $(99 \%)$ & AN $(0 \%) \mathrm{HS}(1 \%)$ \\
Location & CC $(23 \%)$ & SU $(60 \%)$ VI $(17 \%)$
\end{tabular}

\section{Notes:}

FH:freehold RE: rented house QA: quarters

SS:single storied TS:two storied TM:three or more storied SE:separated house AN:annexes HS:housing scheme CC:house in city center SU:house in suburban VI:house in village

Thus, the probability $(\mathrm{P})$ of willingness for the freehold ownership (FH) of a house of a randomly selected person is $97 \%$. It can be expressed as, $\mathrm{P}(\mathrm{FH})=97 \%$. Similarly, $P(R E)=3 \% . P(Q A)=0 \% . P(C C)=23 \%$ and so on

In the same way, the probability of one who prefers to buy freehold ownership of a house in a city center can be computed as,

$$
\{[\mathrm{P}(\mathrm{FH})] \times[\mathrm{P}(\mathrm{CC})]\}
$$

Thus, $P(F H) \times P(C C)=0.97 \times 0.23=22 \%$

Having omitted zero and small percentages of preferences, following values of consumer preferences can be used to find effective potential housing markets.

\begin{tabular}{llll} 
Attributes & \multicolumn{3}{c}{$\%$ Preferences for each aspect } \\
Ownership & FH (97\%) & omitted & omitted \\
Structure & SS (58\%) & TS (41\%) & omitted \\
Arrangement & SE (99\%) & omitted & omitted \\
Location & CC $(23 \%)$ & SU $(60 \%)$ & VI $(17 \%)$
\end{tabular}

Accordingly substantially potential markets can be identified as follows.

Table 1 - Types of potential markets

\begin{tabular}{|c|c|}
\hline Market & Size \\
\hline $\begin{array}{l}\text { Those who prefer to buy freehold interest of single storied separate houses in suburban } \\
\text { areas. FH (97\%).SS }(58 \%) \text {. SE }(99 \%) \text {. SU ( }(60 \%)\end{array}$ & $\begin{array}{l}33 \% \text { of the } \\
\text { sample }\end{array}$ \\
\hline $\begin{array}{l}\text { Those who prefer to buy freehold interest of two storied separate houses in suburban areas. } \\
\text { FH }(97 \%) \text {. TS }(41 \%) \text {. SE }(99 \%) \text {. SU }(60 \%)\end{array}$ & $\begin{array}{l}24 \% \text { of the } \\
\text { sample }\end{array}$ \\
\hline $\begin{array}{l}\text { Those who prefer to buy freehold interest of single storied separate houses in city centers. } \\
\mathrm{FH}(97 \%) \text {. SS }(58 \%) \text {. SE }(99 \%) \text {. CC ( } 23 \%)\end{array}$ & $\begin{array}{l}13 \% \text { of the } \\
\text { sample }\end{array}$ \\
\hline $\begin{array}{l}\text { Those who prefer to buy freehold interest of single storied separate houses in villages. FH } \\
(97 \%) \text {. SS }(58 \%) \text {. SE }(99 \%) \text {. VI (17\%) }\end{array}$ & $\begin{array}{l}10 \% \text { of the } \\
\text { sample }\end{array}$ \\
\hline $\begin{array}{l}\text { Those who prefer to buy freehold interest of two storied separate houses in suburban } \\
\text { centers. FH }(97 \%) \text {. TS }(41 \%) \text {. SE }(99 \%) \text {. SU (60\%) }\end{array}$ & $\begin{array}{l}09 \% \text { of the } \\
\text { sample }\end{array}$ \\
\hline $\begin{array}{l}\text { Those who prefer to buy freehold interest of two storied separate houses in villages. FH } \\
(97 \%) \text {. TS }(41 \%) \text {. SE }(99 \%) \text {. VI (17\%) }\end{array}$ & $\begin{array}{l}07 \% \text { of the } \\
\text { sample }\end{array}$ \\
\hline
\end{tabular}

\section{Relatively important determinants in a purchase decision}

Study identified that the "Location" of a house is the most relatively important determinant in a purchase decision. However, it is not the dominant factor. Among evaluated factors, "quality of construction", "price", "legality", "facilities", and "neighborhood" also are more important closely as important as the location. Particularly "Price" is the most important determinant for the employees who are in "below to clerical". Further, females pay the highest attention on the "additional sections" of a house. In all events, "location" has the highest level of preference, which is either around 12\% or $13 \%$ of weighted average.

In addition, to the design of a house, the size of a house, and the marketability, etc; could be recognized as the moderately influential determinants in a housing purchase as a whole. And the additional sections of a house are the least influential determinants in general.

\section{Market Segmentations}

Demographic variables are not highly effective criteria for the segmentation of the housing market according to this sample. Chi-Squire test revealed that considered some demographic variables and the other determinants are independent. Rank Correlation Coefficient test also proved that the considered demographic variables do not have notable different patterns of relative importance of each determinant. Yet, the test result shows some potential effects of demographic variables as explain below.

Table 2 - Summery of the Chi-Squire test

\begin{tabular}{|l|c|c|l|}
\hline \multicolumn{1}{|c|}{ Segment } & Computed Chi value & Chi- value in the table & \multicolumn{1}{c|}{ Remarks } \\
\hline Age & 0.49 & 5.99 & Two categories are independent \\
\hline Sex & 76.81 & 5.99 & Two categories are not independent \\
\hline Income & 4.34 & 5.99 & Two categories are independent \\
\hline Occupation & 12.6 & 12.59 & Two categories are no independent \\
\hline
\end{tabular}

Computed Chi- values of age and income levels are smaller than the relevant Chi-values in the table at 5\% significant level. Therefore, the first hypothesis of these events is accepted. It states that those two categories of variables are independent. It means that such demographic factors i.e. age and income, are not making a significant influence on the determinants reflected as marketing mix variables. Therefore, age and income level cannot be suggested as effective criteria for the market segmentation according to this particular sample.

However, as far as the sex is concerned, the computed Chi-value is grater than that in the standard table. It implies that the sex and the considered other variable i.e. marketing mix variables are not independent. Therefore, sex as a criterion for market segmentation has a significant effect. This is true with the fact that is relatively most important determinant of male is the "location" whereas for the female it is the "additional sections".

Likewise, the occupational level has a significant impact on the buying decision of a house. In this study, except "below clerical" other occupations are equally interested with the location of a house. That is why both Chi-values are equal. 
Accordingly, two groups tested, sex and occupation are not independent. Therefore, it can be concluded that such demographic variables are statistically significant factors for the housing market buying behavior. Further it is clear that the segmentation of the housing market based on those demographic variables with a view to reach marketing objectives has some effect and meaning.

Rank correlation coefficient test: This coefficient can be used to determine whether the patterns of relative importance on each determinant according to different market segments, have the same directions or not. If series of ranked values are in the same pattern or direction, it is clear that such market segments posses a similar set of preferences, desires etc. Therefore, dividing buyers into such groups will not be workable in terms of market segment. In other words, considered

\begin{tabular}{|l|c|c|}
\hline \multicolumn{1}{|c|}{ Segment } & Correlation Coefficient $\left(\mathbf{r}_{\mathbf{k}}\right)$ & \multicolumn{1}{c|}{ Remarks } \\
\hline Age & 0.968 & Two data series have the same pattern \\
\hline Sex & 0.434 & Two data series have the same pattern \\
\hline Income & 0.937 & Two data series have the same pattern \\
\hline Occupation & 0.953 & Two data series have the same pattern \\
\hline
\end{tabular}

market segmentation criteria are not effective. Following is the test results.

\section{Table 3 - Ranked correlation coefficient results}

According to the theoretical interpretation, if $r_{k}>0$ the ranked series of data have the same pattern. Therefore, the above table shows that all $r_{k}$ values are grater than the zero. This means that tested two data series exhibit the same pattern. However, $r_{k}$ value of the sex is little closer to the zero when it is compared to the others. However, as a whole, it can be concluded that this test also proves that the evaluated demographic variables are not much meaningful criteria for the market segmentation in the housing market according to this particular sample.

\section{Conclusion}

Housing market studies in Colombo is a need of the time. After liberalized economic polices, private sector activities in the housing market is growing significantly. At the same time, housing market opportunities at present and in the future are very high. Therefore, the contribution of the study is useful for the enhancement of the market.

Determination of efficient housing markets is widely based on clear understanding of consumer behavior in the market. This study provides some sort of guideline to analyze and identify consumers' needs and wants to a certain extent. This study also reveals the need of further analysis of market segmentations. For instance, according to this sample evaluated demographic variables are not very effective criteria for market segmentation. All in all, this study encourages further studies in different views of the housing market.

\section{Reference:}

Apgar, M. (1995) "Managing real estate to build value", Harvard Business Review, (Nov-Dec): 162-179

Arimah, B.C. (1992) "An empirical analysis of the demand for housing attributes in a third world city." Land Economics (Nov.), 68(4): 366-379

Beron, K.J. et. al., (1997), "Analysis of the housing market before and after the 1989 Loma Prieta earthquake", Land Economics, (Feb): 101-113

Chandrakanti T.P.G. (1994) "A study of the present development of the condominium in Colombo", EMV Collection, Department of Estate Management and Valuation, University of Sri Jayewardenepura.

Davis, H.L. (1976), "Decision making within the household", Journal of Consumer Research: An Interdisciplinary Quarter 2 (4): 241-260

Dodankotuwa, J.B. (1998), "An Overspill Policy-New Town A Myth or A Reality?", $25^{\text {th }}$ Anniversary B.Sc. Estate Management and Valuation (SP) Degree-University of Sri Jayewardenepura. P. 25-28

Embuldeniya, R.N. (1996) "Healthy residential environment for low income settlement" EMV Collection, Department of Estate Management and Valuation, University of Sri Jayewardenepura

Galster, G. and Williams, Y. (1994) "Dwellings for the severely mental disabled and neighborhood property values: The details matter." Land Economics (Nov.): 466-477

Jagoda, D (2000), "Sustainable housing development for urban poor in Sri Lanka: Recommendation for the improving relocation housing projects in Colombo" in www.lchs.se/TRAINING/postgrad/ AD/papers/2000/14_AD2000.pdf

King, D.A. and J.A. Sinden (1994) "Price formation in farm land market", Land Economics (Feb): 3852

Kotler, P. et al (2007), "Marketing Management: A South Asian Perspective, $12^{\text {th }}$ Ed., Delhi, 110017, India

Kotller, P. (1991), Marketing Management; analysis, planning, implementation, and control; $7^{\text {th }}$ edition, Prentice Hall Inc; USA

Mackmm, D (1994) "The valuation and sale of residential property", $2^{\text {nd }}$ edition, Routledge London New York 
Nanayakkara, S. et al (2006) "Factors affecting condominium development in Sri Lanka", Built Environment Sri Lanka, 07(01): 23-28

Nickels, W.G. (1982) "Marketing Principles", 2nd edition, Prentice Hall Inc. New Jersey.

Premathilaka, H M. (1999), "Determinants of urban land values in Colombo city and suburban", The annual research session 2000/2001 of FMSC, University of Sri Jayewardenepura, Sri Lanka

Ratnayake, A.B.B. (1991) "Private sector housing in Sri Lanka.", Unpublished research paper, Postgraduate Institute, University of Sri Jayewardenepura, Sri Lanka

Saunders, P (1990), "A nation of home owners", Academic division of Unwin Hyman Ltd, London

Senaratne, P.W. (1998) "Some Notes on Valuation, Value as a Market Concept and Looking Towards the Millennium" $25^{\text {th }}$ Anniversary B.Sc. Estate Management and Valuation (SP.) Degree-University of Sri Jayewardenepura: 10-19

Shim, J.K., Shim, J., Hartman, S.W. (1996) "Dictionary of Real Estate" Business Dictionary series John Wiley and sons Inc. New York USA

Stanton, W.J. et al (1994) "Fundamental of marketing" $2^{\text {nd }}$ edition, Mc Graw-hill, Inc New York
Sumanasekara, G.L. (1996) "A comparative study on different credit facilities available for housing", EMV Collection, Department of Estate Management and Valuation, University of Sri Jayewardenepura, Sri Lanka

Turnbull, G.K. (1992) "Location, housing, and leisure demand under local employment", Land Economics (Feb): 62-71

Urban, G.L. et al, (1993) "Pre-market forecasting for new consumer durable goods; modeling, categorizing, elimination, and consideration phenomena", Journal of marketing, 57(2): 47-63

Vipula, W. (1995) "The impact of source credibility on consumer buying", Unpublished Research paper, Postgraduate Institute of Management, University of Sri Jayewardenepura, Sri Lanka

Weimer, A M (1960) "Principles of real estate", The Ronald press company New York.

Wijeweera, C A (2003) "Condominium development and the condominium law" in Associated Newspaper Ltd

Zainuddin, N. et al (2006), "Horizontal housing property market”, Built Environment Sri Lanka, 07(01): pp. 16-22 